\title{
Organic Tomato Production in Alabama: Host Preference of the Tomato Hornworm (Manduca quinquemaculata) and Performance of Selected Biopesticides
}

\author{
Sonu Koirala B. K. ${ }^{1,2}$, Franklin Quarcoo ${ }^{1,}$, , Kokoasse Kpomblekou-A ${ }^{1}$, Desmond Mortley ${ }^{1}$ \\ ${ }^{1}$ Department of Agricultural and Environmental Sciences, Tuskegee University, Tuskegee, USA \\ ${ }^{2}$ Department of Entomology, Pennsylvania State University, College Station, USA
}

\section{Email address:}

skoirala4947@tuskegee.edu (Sonu K. B. K.), fquarcoo1@tuskegee.edu (F. Quarcoo), kkpomblekou@tuskegee.edu (K. Kpomblekou-A), dmortley@tuskegee.edu (D. Mortley)

${ }^{*}$ Corresponding author

\section{To cite this article:}

Sonu Koirala B K, Franklin Quarcoo, Kokoasse Kpomblekou-A, Desmond Mortley. Organic Tomato Production in Alabama: Host Preference of the Tomato Hornworm (Manduca quinquemaculata) and Performance of Selected Biopesticides. American Journal of Entomology. Vol. 5, No. 1, 2021, pp. 10-17. doi: 10.11648/j.aje.20210501.12

Received: March 2, 2021; Accepted: March 30, 2021; Published: April 26, 2021

\begin{abstract}
Organic farming largely excludes the use of chemical fertilizers, synthetic pesticides, genetically modified organisms, antibiotics, and growth hormones. Organic food production in the Southeastern United States is low and not reflective of the national trend. Warm temperatures and high rainfall patterns in this region cause a rapid decomposition of soil organic matter and high insect pest populations; both conditions do not augur well for vegetable production. The specific objectives of this study were to (1) conduct insect host-preference assessments using three popular tomato cultivars and 2) assess efficacy and cost effectiveness of selected biopesticides against tomato hornworm. Field trials involving three tomato cultivars: Celebrity, Mountain magic and Rocky top were conducted at the George Washington Carver Agricultural Experiment Station Organic Research Farm, Tuskegee University Alabama in 2018 and 2019. The experiments were set up as a Completely Randomized Design (CRD) with $3 \times 4$ factorial treatment arrangement (i.e., 3 tomato varieties and 4 spray treatments) replicated 4 times. An assessment of relative performance and cost-effectiveness of the biopesticide active ingredients: Azadirachtin, Spinosad, and Pyrethrin against hornworms on tomato was done. An improvised Economic threshold (ET) of one adult hornworm per 10 foot-row of tomatoes was used. Biopesticides were sprayed on designated plots when visual sampling revealed the attainment of ET populations. The hornworm counts at different sampling dates were analyzed using SAS statistical software. Tomato hornworms showed equal preference for Celebrity, Mountain magic and Rocky top tomato cultivars. Plots treated with the candidate biopesticides recorded similar hornworm populations as untreated control plots in 2018 whereas in 2019, Spinosad and Azadirachtin performed better than the control. Based on the total volume of biopesticide used, per unit cost of each biopesticide, and reduction of hornworms in treated plots, none of the biopesticides was cost-effective in 2018. This is because none of them was effective (i.e., performed better than untreated controls) against the hornworm. In 2019, however, the use of Spinosad and Azadirachtin resulted in hornworm counts that were significantly lower than those recorded in the control study. However, these significant differences in hornworm populations did not translate into differences in tomato yields. Except for a significantly lower hornworm population observed approximately 57 DAT, pyrethrin treatments resulted in hornworm populations that were comparable to those recorded on control plots. Insignificant effects on tomato yield renders moot, any computations of cost-effectiveness. Pyrethrin is clearly the least expensive option but cannot be described as the most cost-effective.
\end{abstract}

Keywords: Organic Farming, Tomato Hornworm, Economic Threshold, Biopesticides, Spinosad, Azadirachtin, Pyrethrin 


\section{Introduction}

The tomato hornworm, Manduca quinquemaculata (Haworth), is an important pest of solanaceous vegetables such as tomato, tobacco, eggplant, potato, and pepper. The feeding activity of the larvae is initially focused on the Shoot Apical Meristem (SAM) regions (i.e., young leaves, blossoms, and young fruits); the larvae later feed on older foliage and generally cause heavy defoliation of tomato plants. The final larval stage can consume about $90 \%$ of the foliage [1]. The cryptic coloration of the larvae (i.e., pale green color) helps it to blend in with tomato leaves and branches; this makes effective scouting a time-consuming exercise. The presence of hornworm fecal pellets on leaf surfaces, base of plants [2] and plastic mulch, are important indirect diagnostic signs of the incidence and severity of this pest.

Management of tomato hornworms is largely based on use of synthetic pesticides. Efficacy studies involving dust formulations of pesticides such as Krytox, Cryolite, Calcium arsenate, Phthalonitrile, and Paris green against the tomato hornworm have however, produced a range of varying results [3]. Available literature on the performance of synthetic foliar and systemic insecticides also reveals varying performances against the hornworm on different cultivars of tomatoes [4-8]. Indiscriminate use of agrochemicals has contributed significantly to several environmental issues. These environmental issues include pollution and eutrophication of water bodies due to runoff of excess synthetic fertilizers and pesticides into surface water bodies [9]. Over-reliance on broad-spectrum synthetic pesticides such as organochlorines, organophosphates, carbamates, and pyrethroids worsens this environmental impact by causing death of non-target beneficial insects as well as target insect pests [10]. An experiment conducted on toxicity of thiacloprid pesticides against the insect predator Macrolophus pygmaeus (Hemiptera: Miridae), showed $100 \%$ mortality of the Macrolophus nymph [11]. Mortality of beneficial insects (such as predators of crop pests), results in adverse effects (such as relaxation in feeding pressure) on insect pests which in turn leads to increases in the population of affected pests. Thus, the excessive use of chemical-based pesticides results in outbreak or resurgence of pests which necessitates more intensive use of pesticides. Such pest management practices generally result in higher levels of dependency on pesticides [12-14]. The natural quality, unique mode of action, narrow spectrum of activity/target organisms, and generally low use volume are all characteristics that make biopesticides particularly useful in the quest to address some of the factors responsible for development of insecticide resistance in insect pests.

Various biological control techniques have been tested against the tomato hornworm. This includes a wide range of methods such as the use of vermicompost $[15,16]$, blacklight $[17,18]$, microbial bio-pesticides [19-21], and mass release of predators and parasitoids [22]. A greenhouse and a field study conducted to evaluate the efficacy of food-waste vermicompost at different doses against tomato hornworm showed a significant reduction in hornworm damage in plants supplied with 1.25 and $2.5 \mathrm{t} \mathrm{ha}^{-1}$ of the vermicompost relative to plants supplied with inorganic-fertilizers as a nutrient source [15]. Plant intake of soluble phenolic compounds from aqueous extracts of the vermicompost cause a reduction in pest pressure and attack; this is because these compounds have insect repellent properties and exert adverse effects on the reproduction and survival rates of certain pests [16]. Available literature shows a long history of efficacy of biological control agents against the tobacco hornworms (Manduca sexta [Johannson]). A 1969 study conducted in Southern California on early plantings of tomatoes (grown for processing) showed significant performance of Trichogramma pretiosum Riley when releases were done two times per week at the rate of 465,000 parasitoids/acre in summer [22]. A field trial conducted in Ontario Canada revealed that the entomopathogen Bacillus thuringiensis var. thuringiensis Berliner was as effective as endrin, Guthion or endosulfan in reducing feeding injury done by tobacco and tomato hornworms to burley tobacco [19]. A similar result was reported when Speight tobacco plants were treated with various formulations of $B$. thuringiensis var. kurstaki against tomato hornworm at Oxford, North Carolina [20].

A multi-year study conducted on the use of black light for the management of the tomato hornworm did not reveal any significant effects on the hornworm populations relative to the control plots throughout the study [17]. Similar results were obtained in a 2-year study conducted in Kentucky [18]. A field study on the relative efficacy of the biopesticides, Xentari DF (a.i. B. thuringiensis), PyGanic 5.0 EC (a.i. Pyrethrin), Neem oil (a.i. Azadirachtin) and Pyola EC (a.i. Pyrethrin) at two different locations in Alabama, failed to show any appreciable performance of these products in protecting tomato fruits from major tomato worms including the tomato hornworm [21]. The high cost of organic pesticides and reports of treatment failures make research into the improvement of these bioinsecticides, an imperative. Such research is particularly critical in the southeastern United States where insect pests represent one of the most limiting factors to vegetable production. The high ambient temperatures and relative humidity levels augur well for the rapid development and multiplication of insects. The feeding activity of high populations of various major insect pests, results in devastating effects on crop production enterprises in this region. In Alabama and some other states in the Southeastern United States, there is a dearth (or in some cases total lack) of site-specific organic pest management recommendations pertaining to relevant economic thresholds and the effective use of recommended organic pesticides against major insect pests of several vegetable crops. Therefore, the major objectives of this research were to (a) evaluate the efficacy of selected commercially available OMRI-listed biopesticides for the management of the tomato hornworm (b) to determine the relative preference of the tomato hornworm for three tomato varieties that are commercially grown in Alabama, and (c) evaluate the relative cost effectiveness of these biopesticides in the management of the tomato hornworm on tomatoes in Alabama. 


\section{Materials and Methods}

\subsection{Plant Material and Experimental Design}

The field experiments were conducted during the summer of 2018 and 2019 at the Organic Farming Research Unit of the George Washington Carver Agricultural Experiment Station (GWCAES) at Tuskegee University in Alabama. Three cultivars of tomatoes: Celebrity, Rocky top and Mountain magic were selected based on their commercial importance in the Southeast United States. Seeds of each variety were sown in growing media with a $1: 2$ ratio of compost and soil in an organic greenhouse on March $7^{\text {th }}$ and March $6^{\text {th }}$ in 2018 and 2019, respectively. To improve soil fertility and nutrient status at the site, eight different species of cover crop namely: Taproot Radish, Crimson Clover Raw, Fava Beans, Hairy Vetch Raw, Buckwheat, Black Oats, Winter Barley and Abruzzi) were planted in winter of 2017 and 2018. In spring of the following year and two weeks before planting, the cover crops were cut down to dry and incorporated into soil. Soil samples were collected at $15 \mathrm{~cm}$ depth and analyzed for phosphorus, potassium, manganese, and other nutrients at the Auburn University Soil Testing Laboratory. Three rows of raised beds [ $10 \times 2 \times 0.5 \mathrm{ft}$ each] with center to center spacing of $5 \mathrm{ft}$ were made for each subplot. Plant to plant distance was 1 foot. An Organic fertilizer 4-3-4 (Mighty Grow Inc., Fruitdale, AL) was applied in band 6 inches away from the planting row root at a rate of $125 \mathrm{~kg} / \mathrm{ha}$. The raised beds were subsequently covered with a white plastic mulch Seven and half-week tomato seedlings were transplanted in the center of each bed ( $5 \mathrm{ft}$. wide) a foot apart. In the repeat study carried out in 2019, plant to plant and center to center distances were 2 feet and 6 feet, respectively. Each row (i.e., raised bed) was 20 feet long $2 \mathrm{ft}$ wide and $0.5 \mathrm{ft}$ high. A total of 10 plants were planted per row of each three-row subplot in both years. The experiments were set up and analyzed each year as a Completely Randomized Block Design (CRD) with a $3 \times 4$ factorial treatment arrangement (i.e., 3 cultivars and 4 treatments made up of 3 biopesticides and a control plot that were treated with water). There were 48 (3-row) subplots.

\subsection{Bio-pesticides Application and Data Collection Procedure}

The four treatments were Pyrethrin, Azadirachtin, Spinosad and a control (water only). To minimize edge effects on insect counts, the middle of each three-row subplot was visually sampled once a week to determine the attainment (or otherwise) of economic threshold populations. In both studies, the first visual sampling was done 33 days after transplanting (DAT). The pesticide application protocol in 2018 differed considerably from that of 2019. In 2018 a "spot application" method was used; only subplots that attained the ET were sprayed with the respective biopesticides or water (for the control plots). In 2019 the attainment of ET on a replication (i.e., subplot of a treatment) resulted in the treatment of all replications of that treatment. Attainment of the ET resulted in application of biopesticides in the evening of the same day of the visual samplings. Based on the attainment of the ET, biopesticides were first applied to all pesticide-designated plots 43 DAT. Spinosad-designated plots were not treated 50 DAT because no tomato hornworms were recorded on these plots. This pesticide application protocol effectively resulted in the weekly application of treatment to all plots from the date of first attainment of economic threshold populations until the last pesticide application on 64 DAT. Three (15-liter capacity) Knapsack sprayers $\left(\right.$ Solo $^{\mathrm{R}}$ Incorporated, Newport News, VA) were used for the application of the biopesticides; a sprayer was assigned to a specific biopesticide throughout the study. Insect data were square root-transformed prior to statistical analysis but non-transformed data are presented in the table of results. Insect numbers were statistically analyzed using the PROC MIX procedure of SAS (Version 9.4, SAS Institute, Inc., Cary, NC). In instances where the omnibus F-test indicated significant effects of a factor (s), Tukey's honest significance test was used to determine specific differences between the means of the various factors. Irrespective of the pesticide application protocol used, all plots were sprayed an equal number of times in 2018 and 2019. The total volume of each bio-pesticide used on each subplot was recorded and analyzed. The actual volume of each biopesticide used and the purchase price per unit volume of each biopesticide were used to calculate in respective costs. This data was used to evaluate the relative cost-effectiveness of the three bio-pesticides. The relative cost-effectiveness of the biopesticides was calculated using data on the quantum of crop loss prevented due to the application of biopesticides, the amount of pest reduction, and the total cost of the volume of each biopesticide used in the management of the tomato hornworm.

\section{Results and Discussion}

\subsection{Biopesticide Performance Against the Tomato Hornworm in 2018}

In 2018, there were no significant impacts of the bio-pesticide treatments on the population of tomato hornworms and there was no interactive effects of varieties and treatments on tomato hornworm population. Application of the biopesticides after weekly visual sampling was ineffective on the tomato hornworm population. It is important to note that the biopesticides were not applied after the visual sampling carried out 43 DAT because no hornworms were recorded. At 50, 59, 71 and 80 DAT, a generally low number of hornworms were recorded and plots that reached the ET for the hornworm were sprayed. Application of biopesticides however, did not exert any significant effects on hornworm populations relative to the control plots. The fact that pesticides are generally more effective when pest populations are high and less effective when pest populations are low [23], may account for this poor performance of the candidate biopesticides. Pests, such as the tomato hornworm, that cause considerable crop injury per capita, usually attain economic threshold populations at relatively low numerical values 
compared to pests that cost low levels of injury per capita [23]; this may result in statistically insignificant differences in pest numbers between treated and untreated plots even though significant differences in pest damage may be recorded

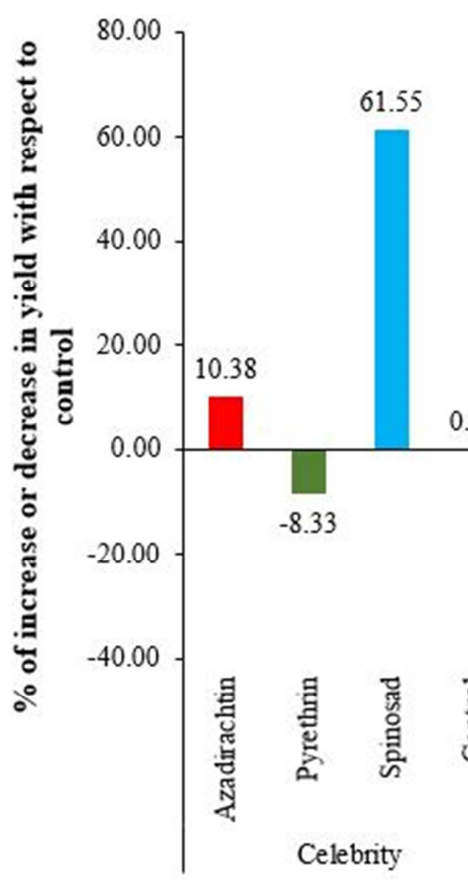

between them. Crop yields (Figure 1) were similar regardless of treatment applied. It is probable that the selected biopesticides were simply not effective under the prevailing environmental conditions at the research site.

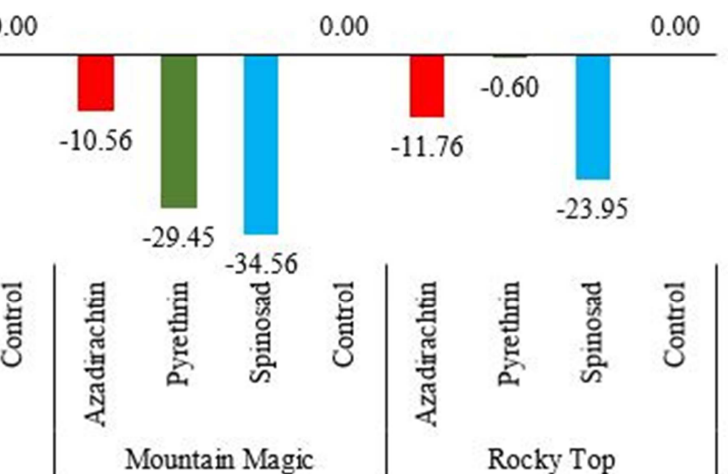

Percentage change in the yield in 2018

Figure 1. Percentage change in tomato yield in 2018.

A few environmental factors exert adverse effects on the efficacy of biopesticides; these include decomposition into less harmful constituents when exposed to water and intense light. This degradation results in residual activities that are generally shorter than conventional (synthetic) pesticides. Pyrethrum, a contact poison, breaks down quickly when exposed to sunlight and water resulting in loss of its residual effectiveness $[24,25]$ on treated surfaces; this biopesticide recorded a half-life of one or two hours in soil [24]. Exposure to sunlight and water cause similar effects on Spinosad; the half-life of spinosyn A (one of its active ingredients) range from 1.6 to 16 days, depending on the amount of sunlight received [26]. In the absence of sunlight, spinosyn A and D (specific constituents of the active ingredient Spinosad) have half-lives of at least 200 days [26]. A thin film of azadirachtin-A exposed to Ultraviolet light was found to have a half-life of 48 minutes [27]; the susceptibility of this compound to light-induced degradation as well as its sensitivity to acidic and basic environments, limit its performance [28, 29]. The rapid rate of photodegradation of these active ingredients, the attendant short residual activities, and the dilution of applied biopesticides (by rainfall) may account partly for the poor performance of the selected biopesticides against the tomato hornworm. These factors generally cause a reduction in the lethality of these biopesticides to levels that may be sublethal to certain target pests. A decision was made to use a revised pesticide application protocol in subsequent studies to determine if there will be marked improvements in the performance of the candidate biopesticides. Changes made include application of pesticides at $6 \mathrm{pm}$ instead of $4 \mathrm{pm}$ to further reduce exposure of biopesticide to sunlight.

\subsection{Biopesticide Performance against the Tomato Hornworm in 2019}

In 2019, the use of a revised pesticide application protocol or other undetermined factors resulted in biopesticide-treated plots recording significantly lower $(\mathrm{P}<0.0001)$ (Table 1) hornworm populations relative to the control plots. The protocol used involved the treatment of all subplots (of a given treatment) upon the attainment of economic threshold populations on at least one replication of that treatment. The observed lower hornworm populations on biopesticide-treated plots however, failed to translate into measurably higher tomato yields (Figure 2); this may be due to the scale of the experiment. No interaction between varieties and biopesticides was observed. Spinosad-treated plots recorded equal number of tomato hornworms with plots treated with Azadirachtin and Pyrethrin but was significantly different from control $(\mathrm{P}<0.05)$ (Table 1). Spinosad has a good track record of performances against lepidopteran herbivores. Spinosad (45\% EC) sprayed at the rate of 73 to $84 \mathrm{gm}$ a.i./ recorded significantly higher efficacy against tomato fruit borer (Helicoverpa armigera Hub.) compared to the conventional/synthetic pesticides, Quinalphos (25\% EC), Lambda cyhalothrin (5\% EC), and Cypermethrin (10 EC) [30]. 


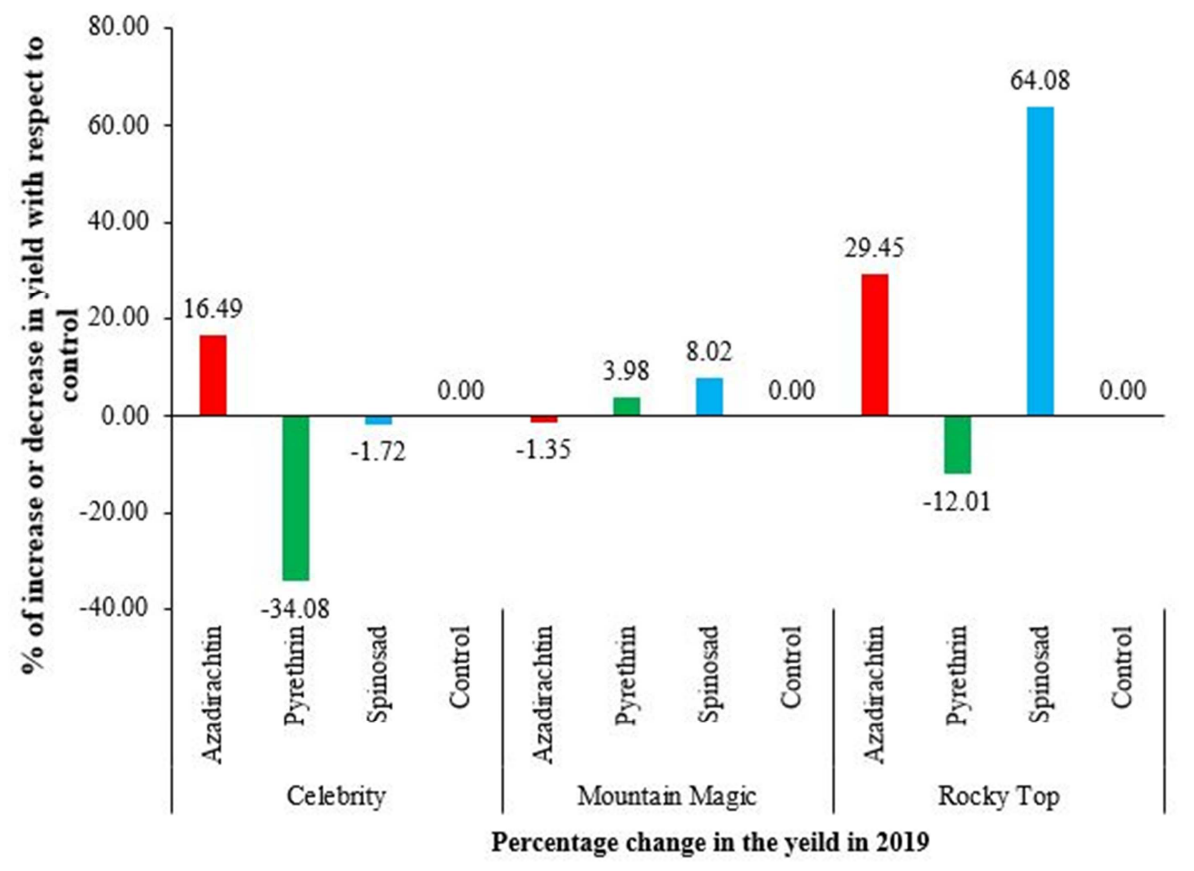

Figure 2. Percentage change in tomato yield in 2019.

The author also reported that the selected dose of Spinosad did not have adverse effects on three natural enemies (predators): a lady beetle (Cheilomenes sexmaculata); a European species of hoverfly (Eupeodes corollae); and the common green lacewing (Chrysoperla carnea). The biopesticides were not sprayed after the visual sampling carried out 50 DAT because of rainfall throughout the week. At 57 DAT, however, Spinosad and Azadirachtin performed significantly better $(\mathrm{P}<0.05)$ than Pyrethrin due to lingering effects of previous pesticide applications. Even though only individual biopesticides were used in this trial, mixtures of certain biopesticides with different active ingredients have been reported to be generally more effective than their individual constituent biopesticides. Biopesticide trials conducted in Cullman, Alabama showed good performance of a mixture of Azadirachtin and Pyrethrin in controlling the larvae of hornworms and other caterpillars.

Table 1. Average number of tomato hornworm observed per experimental unit (10 plants on 20ft x $2 \mathrm{ft}$ middle row) in Summer 2019.

\begin{tabular}{llllll}
\hline Treatment & Rate (oz./acre) & 50 DAT (5 June) & 57 DAT (12 June) & 64 DAT (19 June) & 71 DAT (26 June) \\
\hline Control & - & $0.91 \pm 0.31^{\mathrm{a}}$ & $3.42 \pm 0.69^{\mathrm{a}}$ & $1.83 \pm 0.53^{\mathrm{a}}$ & $0.08 \pm 0.08^{\mathrm{a}}$ \\
Pyrethrin & 17 & $0.41 \pm 0.19^{\mathrm{ab}}$ & $1.17 \pm 0.38^{\mathrm{b}}$ & $0.83 \pm 0.36^{\mathrm{ab}}$ & $0 \pm 0^{\mathrm{a}}$ \\
Azadirachtin & 16 & $0.08 \pm 0.08^{\mathrm{ab}}$ & $0.08 \pm 0.08^{\mathrm{c}}$ & $0 \pm 0^{\mathrm{b}}$ & $0 \pm 0^{\mathrm{a}}$ \\
Spinosad & 10 & $0 \pm 0^{\mathrm{b}}$ & $0 \pm 0^{\mathrm{c}}$ & $0 \pm 0^{\mathrm{b}}$ & $0 \pm 0^{\mathrm{a}}$ \\
p-value & & $* *$ & $* *$ & $* *$ & NS \\
\hline
\end{tabular}

Means within a column followed by the same letter are not significantly different $(\mathrm{P} \leq 0.05)$.

The researchers also reported that tomato plants that were drenched with Azadirachtin recorded significantly $(\mathrm{P}<0.05)$ lower fruit damage [21] relative to untreated plots. Results from the current study involving three individual biopesticides, showed that these products were effective in managing the hornworm. The weekly biopesticide applications resulted in a significant $(\mathrm{P}<0.0001)$ reduction in hornworm populations relative to the control plots. Visual sampling of plants 64 DAT showed that Azadirachtin and Spinosad-treated plots recorded no hornworms which was significantly $(\mathrm{P}<0.05)$ lower than the untreated/control plots $(1.83 \pm 0.53)$ but similar $(\mathrm{P}>0.05)$ to the Pyrethrin-treated plots $(0.83 \pm 0.36)$. Even though the candidate biopesticides were effective in the 2019 trial, the kind of poor performance/treatment failure recorded in the 2018 study has been reported by some other researchers. In a study conducted on tobacco plants in 2013, Dipel, a Bacillus thuringiensis $(\mathrm{Bt})$ product performed better than untreated controls, but pyrethrin-treated plots recorded similar populations $(\mathrm{P}>0.05)$ of non-parasitized hornworms as untreated controls [31]. In a repeat study involving different candidate biopesticides conducted in 2016, the authors reported that plots treated with Spinosad and Azera (in different pesticide formulations) at 7 and 14 days after treatment, recorded significantly lower $(\mathrm{P}<0.05)$ tomato and tobacco hornworm populations relative to untreated control plots [32]. Plots treated with two different microbial pesticides however, performed similarly $(\mathrm{P}>0.05)$ to the untreated control plots. A review of literature on performance of biopesticides is replete with inconsistent and sometimes contradictory results in different years of multi-year studies. In 
the current study, visual sampling conducted 71 DAT failed to show better performance of the biopesticides relative to the control experiment. This is probably because the last biopesticide application prior to this sampling (conducted 64 DAT) was carried out at a time when the tomato plants were senescing. The onset and progression of senescence resulted in a progressive reduction in hornworm populations across all plots, irrespective of treatment. As indicated earlier, low insect pest populations generally render pesticides less effective. The reduction in hornworm populations at this stage of plant growth can be attributed to the fact that hornworms are primarily foliage feeders with a preference for fresh green leaves [33]; senescence therefore rendered the tomato host plants less desirable to this voracious pest. The authors reported that larvae of the tobacco hornworm (Manduca sexta [a close relative of the tomato hornworm]) fed on younger tomato leaves consistently recorded faster growth than their counterparts fed on older tomato leaves. This finding is consistent with the observed preference of numerous other lepidopteran plant feeders for younger leaves reported [34, 35]. This list of lepidopteran herbivores includes $M$. sexta, a sister species of $M$. quinquemaculata. This preference is frequently correlated with higher contents of nitrogen and water as well as lower allelochemical contents in younger leaves [36]. Young tobacco plant leaves have higher protein content relative to older plants [37]; this observation holds true for tomato plants as well.

\subsection{Insect Host-preference Assessment in Tomato}

From the field experiment, in 2018 tomato hornworm showed similar preference for Celebrity, Mountain Magic, and Rocky top tomato cultivars. No interactive effects of tomato variety and sampling date on hornworm populations was observed. Similar results were recorded in the repeat study conducted in 2019; hornworms exhibited a statistically similar preference for all the tomato varieties used in the study. Like observations made in 2018, no interactive effects of tomato variety and sampling date was observed on hornworm populations. The lack of statistically discernible differences in tomato host preference by the tomato hornworm is consistent with findings of others where naive hatchlings of the tobacco hornworm can feed and grow successfully on several different plants or artificial diets [38]. The moth larvae, however, become specialist feeders once they feed on a natural host. The researchers showed that the induced feeding preference of the tobacco hornworm ( $M$. sexta [a close relative of the tomato hornworm]), involves formation of a template to indioside $\mathrm{D}$, which is steroidal glycoside present in the foliage of solanaceous plants. They reported that the ability of the tobacco hornworm to tune its taste receptors to indioside $\mathrm{D}$ is based on a recognition template that is pre-constructed. The authors used this to explain why the taste receptors of hornworm larvae fed on host plants show an increased response to indioside $\mathrm{D}$ relative to other plant compounds that were tested. This was described as a response acquired through previous experience with a host plant. This same host acceptance pathway probably applies to the choice between different varieties of a crop such as the tomato. Feeding of caterpillars on any given tomato variety sets off the set of reactions (described above) culminating in the recognition and acceptance of that variety as a host.

The current study strongly suggests that the adult moth does not discriminate between tomato varieties in the selection of egg-laying sites. The absence of a statistically discernible host preference is therefore consistent with the mechanism by which this pest finds and accepts its host plants.

\subsection{Relative Cost-effectiveness of Candidate Biopesticides in the Management of Economically Important Insect Pests of Tomato}

It is important to note that the candidate biopesticides were applied an equal number of times on designated plots in both 2018 and 2019 studies. Failure to achieve any statistically significant reduction in hornworm populations relative to untreated plots in 2018 showed that the biopesticides were not effective and thus not cost-effective in managing hornworms under the conditions of the study. Based on the total quantity of biopesticide used per unit area, Pyrethrin (\$235.49/acre) the least expensive product resulted in the lowest quantum of financial loss compared with Azadirachtin (\$275.27/acre) and Spinosad (\$330.62/acre) but was neither effective nor cost-effective. No significant effect on tomato yields were observed regardless of treatment (Figure 1); this may or may not be due to the (small) scale of the experiment. No interactive effects between tomato variety and biopesticide treatment on tomato hornworm was observed. In the study conducted in 2019, the use of Spinosad and Azadirachtin resulted in higher reductions in tomato hornworm populations relative to Pyrethrin treated plots $(\mathrm{P}<0.001)$ during certain parts of the growing season (Table 1). There was, however, no significant difference in tomato yields from biopesticide-treated and control plots (Figure 2). Assuming that this is not a scale-effect, this observation renders the previously discussed computations of cost-effectiveness, a moot point. Results from this study show that statistically significant reductions in pest numbers do not necessarily translate into measurable reductions in crop loss. To justify the use of biopesticides, pest population reductions must translate into reductions in plant injury which must ultimately translate into a measurable reduction in crop damage (relative to the untreated controls); the monetary value of crop loss prevented must be higher than the total cost of deploying the biopesticide. Like the observations made in 2018, no significant interactive effects of tomato variety and treatment on crop yield was recorded. Results from the 2019 study clearly showed Pyrethrin (\$229.23/acre) as the most "cost-effective" (or more appropriately, the "least expensive") biopesticide for managing the tomato hornworm. As discussed previously, this is mainly because of the relatively low cost of the total amount of this product used. Given the lack of significant impacts on yield, the term "least expensive" is more appropriate than "cost-effective" in describing the cost-benefit elements of the use of Pyrethrin to manage the 
tomato hornworm. Non-parametric tests do not require the kind of large sample sizes $(\mathrm{N}>20)$ recommended for parametric toxicological tests to detect differences (if any) between treatments [39]. A higher sample size, however, increases the power of both parametric and non-parametric tests depending on the normality of the data set. Even though the current study is a non-parametric one, it is possible that an increase in the sample size or the size of the experimental units/plots may make it possible to detect differences in yield between biopesticide treatments and untreated controls.

\section{Conclusion and Future Research}

None of the selected biopesticide proved to be effective in managing the tomato hornworm in 2018, partly because of the generally low number of hornworms recorded. The fact that crop protection (not killing of pests) is the goal of pest management efforts must feature prominently in the evaluation criteria of all pesticides. Under certain conditions, the use of biopesticides might result in numerically significant mortality of hornworms but this may not always translate to measurable reductions in crop loss. In such cases the crop protection goal is not achieved even though pest management expenses are incurred.

It appears that inconsistent performance results observed in different years of multi-year biopesticide trials are not uncommon. The current study is not a conclusive verdict on the efficacy of the selected biopesticide; additional studies on these and other biopesticides are ongoing. Multi-locational trials are particularly important in the quest for research-based and area-specific information on biopesticide performance. Such trials will provide information that will contribute significantly to the successful production of tomatoes under organic systems in the southeastern United States. Such studies afford researchers opportunities to tweak pesticide deployment protocols to improve performance or determine products that may not be effective under environmental conditions that prevail at specific geographical locations. Evaluation of different colored plastic mulches may reveal some significant effects on the incidence and severity of hornworms on tomatoes. Future studies on the relative performance of biopesticide mixtures; various biopesticide rotation schedules, and the use of biopesticides such as Bt products in a general IPM strategy against the pest, may reveal some interesting results. Larger field trials at experiment stations or on large-scale commercial farms will help check for scale-effects on the performance of biopesticides in increasing the harvestable yield of tomatoes. Good record-keeping practices will enable the estimation of production costs which will in turn provide good data for the analysis of cost-effectiveness of biopesticides.

\section{Acknowledgements}

The Southeast Organic Partnership at Tuskegee University is supported by USDA/NIFA Competitive Grant Program, Grant \# 2016-51300-25725.

\section{References}

[1] Villanueva, R. (1998). Tobacco Hornworm, Manduca sexta (Linnaeus), and Tomato Hornworm, Manduca quinquemaculata (Haworth), (Insecta: Lepidoptera: Sphingidae). University of Florida IFAS Extension EENY-031, $1-5$.

[2] Bauernfeind, R. J. (2013). Tomato and Tobacco Hornworms. Kansas State University Agricultural Experiment Station and Cooperative Extension Bulletin MF-3075.

[3] Walker, H. G., \& Anderson, L. D. (1944). Tomato Hornworm Control. Journal of Economic Entomology, 37 (2), 308-308.

[4] Kuhar, T. P., Schultz, P., Doughty, H., Wimer, A., Wallingford, A., Andrews, H., Phillips, C., Cassell, M., \& Jenrette, J. (2011). Evaluation of foliar and soil-applied insecticides for the control of foliar insects in fall tomatoes in Virginia, 2010. Arthropod Management Tests, 36 (1), E85.

[5] Middlekauff, W. W., Gonzales, C. Q., \& King, R. Q. (1963). Effect of various insecticides in the control of caterpillars attacking tomato in California. Journal of Economic Entomology, 56 (2), 155-158.

[6] Carson, W. G., Kund, G. S., \& Trumble, J. T. (1999). Effect of insecticides on tomato insects, 1997. Arthropod Management Tests, 24 (1).

[7] Kuhar, T. P., \& Doughty, H. (2009). Evaluation of insecticide treatments for the control of insect pests in snap beans, 2008. Arthropod Management Tests, 34 (1).

[8] Carson, W. G., Kund, G. S., \& Trumble, J. T. (2013). Effect of insecticides on tomato insects, 2012. Arthropod Management Tests, 38 (1), E66.

[9] Sud, M. (2020). Managing the biodiversity impacts of fertilizer and pesticide use: Overview and insights from trends and policies across selected OECD countries.

[10] Coats, J. R. (2012). Insecticide mode of action. Academic Press.

[11] Martinou, A. F., Seraphides, N., \& Stavrinides, M. C. (2014). Lethal and behavioral effects of pesticides on the insect predator Macrolophus pygmaeus. Chemosphere, 96, 167-173.

[12] Weller, S., Culbreath, A., Gianessi, L., Godfrey, L., Jachetta, J., Norsworthy, J.,... \& Madsen, J. (2014). The contributions of pesticides to pest management in meeting the global need for food production by 2050. Issue Paper-Council for Agricultural Science and Technology, (55).

[13] Dutcher, J. D. (2007). A review of resurgence and replacement causing pest outbreaks in IPM. General concepts in integrated pest and disease management, 27-43.

[14] Way, M. J., \& Heong, K. L. (1994). The role of biodiversity in the dynamics and management of insect pests of tropical irrigated rice-a review. Bulletin of Entomological Research, 84 (4), 567-587.

[15] Yardim, E. N., Arancon, N. Q., Edwards, C. A., Oliver, T. J., \& Byrne, R. J. (2006). Suppression of tomato hornworm (Manduca quinquemaculata) and cucumber beetles (Acalymma vittatum and Diabrotica undecimpunctata) populations and damage by vermicomposts. Pedobiologia, 50 (1), 23-29. 
[16] Edwards, C. A., Arancon, N. Q., Vasko-Bennett, M., Askar, A., \& Keeney, G. (2010). Effect of aqueous extracts from vermicomposts on attacks by cucumber beetles (Acalymna vittatum) (Fabr.) on cucumbers and tobacco hornworm (Manduca sexta) (L.) on tomatoes. Pedobiologia, 53 (2), 141-148.

[17] Stanley, J. M., \& Dominick, C. B. (1958). Response of tobacco-and tomato-hornworm moths to Black Light. Journal of Economic Entomology, 51 (1), 78-80.

[18] Jones, G. A., \& Thurston, R. (1970). Effect of an area program using blacklight traps to control populations of tobacco hornworms and tomato hornworms in Kentucky. Journal of Economic Entomology, 63 (4), 1187-1194.

[19] Becg, J. A. (1964). Microbial and chemical control of hornworms attacking tobacco in Ontario. Journal of Economic Entomology, 57 (5), 646-649.

[20] Jackson, D. M. (1983). Control of Tobacco Budworms and Tomato Hornworms with Bacillus Thuringiensis Var. Kurstaki, 1981. Insecticide and Acaricide Tests, 8 (1), 224-224.

[21] Majumdar, A., Caylor, A., \& Pitts, J. (2014). Late-season caterpillar control in tomatoes using bioinsecticide premixes and tank-mixes, 2013. Arthropod Management Tests, 39 (1), E27.

[22] Oatman, E. R., \& Platner, G. R. (1971). Biological control of the tomato fruitworm, cabbage looper, and hornworms on processing tomatoes in southern California, using mass releases of Trichogramma pretiosum. Journal of Economic Entomology, 64 (2), 501-506.

[23] Pedigo, L. P., \& Rice, M. E. (2009). Ecological management of the crop environment. Entomology and pest management, sixth edition. Waveland Press, Inc., Long Grove, IL, 335-368.

[24] Casida, J. E., \& Quistad, G. B. (1995). Pyrethrum flowers: production, chemistry, toxicology, and uses. In International Symposium on Pyrethrum Flowers: Production, Chemistry, Toxicology and Uses, Honolulu, Hawaii (USA), 1992. Oxford University Press.

[25] Extoxnet (1994). Pesticides Management Education Program, Cornell University, NY.

[26] Saunders, D. G., \& Bret, B. L. (1997). Fate of Spinosad in the environment. Down to Earth, 52 (1), 14-20.

[27] Dureja, P., \& Johnson, S. (2000). Photodegradation of azadirachtin-A: A neem-based pesticide. Current Science, 1700-1703.

[28] Johnson, S., Dureja, P., \& Dhingra, S. (2003). Photostabilizers for Azadirachtin-A (a neem-based pesticide). Journal of Environmental Science and Health, Part B, 38 (4), 451-462.

[29] Veitch, G. E., Beckmann, E., Burke, B. J., Boyer, A., Maslen, S. L., \& Ley, S. V. (2007). Synthesis of azadirachtin: a long but successful journey. Angewandte Chemie International Edition, 46 (40), 7629-7632.

[30] Ghosh, A., \& Chatterjee, M. (2009). Bio-efficacy of Spinosad against tomato fruit borer (Helicoverpa armigera Hub.) (Lepidoptera: Noctuidae) and its natural enemies. Journal of Horticulture and Forestry, 2 (5), 108-111.

[31] Toennisson, A., \& Burrack, H. (2015). Efficacy of organically acceptable pesticides against key tobacco pests, 2013. Arthropod Management Tests, 39 (1).

[32] Toennisson, A., \& Burrack, H. (2018). Efficacy of organically acceptable materials against tobacco pests, 2016. Arthropod Management Tests, 43 (1).

[33] Kessler, A., \& Baldwin, I. T. (2002). Manduca quinquemaculata's optimization of intra-plant oviposition to predation, food quality, and thermal constraints. Ecology, 83 (8), 2346-2354.

[34] Kursar, T. A., Wolfe, B. T., Epps, M. J., \& Coley, P. D. (2006). Food quality, competition, and parasitism influence feeding preference in a neotropical lepidopteran. Ecology, 87 (12), 3058-3069.

[35] Barone, J. A. (1998). Host-specificity of folivorous insects in a moist tropical forest. Journal of Animal Ecology, 67 (3), 400-409.

[36] Stamp, N. E., \& Bowers, M. D. (1990). Phenology of nutritional differences between new and mature leaves and its effect on caterpillar growth. Ecological Entomology, 15 (4), 447-454.

[37] Van Dam, N. M., Horn, M., Mareš, M., \& Baldwin, I. T. (2001). Ontogeny constrains systemic protease inhibitor response in Nicotiana attenuata. Journal of chemical ecology, 27 (3), 547-568.

[38] Del Campo, M. L., Miles, C. I., Schroeder, F. C., Mueller, C., Booker, R., \& Renwick, J. A. (2001). Host recognition by the tobacco hornworm is mediated by a host plant compound. Nature, 411 (6834), 186-189.

[39] Wang, M., \& Riffel, M. (2011). Making the right conclusions based on wrong results and small sample sizes: interpretation of statistical tests in ecotoxicology. Ecotoxicology and environmental safety, 74 (4), 684-692. 